\title{
Application of Infrared Spectroscopy to Analysis of Chitosan/Clay Nanocomposites
}

\author{
Suédina M.L. Silva, Carla R.C. Braga, Marcus V.L. Fook, \\ Claudia M.O. Raposo, Laura H. Carvalho and Eduardo L. Canedo \\ Federal University of Campina Grande, Department of Materials Engineering \\ Brazil
}

\section{Introduction}

In recent years, polymer/clay nanocomposites have attracted considerable interest because they combine the structure and physical and chemical properties of inorganic and organic materials. Most work with polymer/clay nanocomposites has concentrated on synthetic polymers, including thermosets such as epoxy polymers, and thermoplastics, such as polyethylene, polypropylene, nylon and poly(ethylene terephthalate) (Pandey \& Mishra, 2011). Comparatively little attention has been paid to natural polymer/clay nanocomposites. However, the opportunity to combine at nanometric level clays and natural polymers (biopolymers), such as chitosan, appears as an attractive way to modify some of the properties of this polysaccharide including its mechanical and thermal behavior, solubility and swelling properties, antimicrobial activity, bioadhesion, etc. (Han et al., 2010). Chitosan/clay nanocomposites are economically interesting because they are easy to prepare and involve inexpensive chemical reagents. Chitosan, obtained from chitin, is a relatively inexpensive material because chitin is the second most abundant polymer in nature, next to cellulose (Chang \& Juang, 2004). In the same way, clays are abundant and low-cost natural materials. Although chitosan/clay nanocomposites are very attractive, they were not extensively investigated, with relatively small number of scientific publications. In addition, the successful preparation of the nanocomposites still encounters problems, mainly related to the proper dispersion of nano-fillers within the polymer matrix. In this chapter, in addition to discussing the synthesis and characterisation by infrared spectroscopy of chitosan/clay nanocomposites, data of x-ray diffraction and mechanical properties are also considered.

\subsection{Chitosan}

Chitosan is a naturally occurring linear polysaccharide, closely related to chitin, a polymer widely distributed in the animal kingdom. The discovery of chitosan is ascribed to Rouget in 1859 when he found that boiling chitin in potassium hydroxide rendered the polymer soluble in organic acids. In 1894 Hoppe-Seyler named this material chitosan. Only in 1950 was the structure of chitosan finally resolved (Dodane \&Vilivalam, 1998, as cited in Dash et al., 2011). Chitin can be extracted from crustacean shells, insects, fungi, insects and other biological materials (Wan Ngah et al., 2011). The main commercial sources of chitin are the 
shell waste of shrimps, lobsters, krills, and crabs. Several millions tons of chitin are harvested annually in the world, making this biopolymer an inexpensive and readily available resource (Dash et al., 2011). Chitosan is found naturally only in certain fungi (Mucoraceae), but it is easily obtained by the thermochemical deacetylation of chitin in the presence of alkali (Darder et al., 2003). Several methods have been proposed, most of them involving the hydrolysis of the acetylated residue using sodium or potassium hydroxide solutions, as well as a mixture of anhydrous hydrazine and hydrazine sulfate. The conditions used for deacetylation determines the polymer molecular weight and the degree of deacetylation (DD) (Dash et al., 2011; Lavorgna et al., 2010).

Chitosan is a copolymer whose chemical structure is shown in Fig. 1. The numbers on the extreme left ring are conventionally assigned to the six carbons in the glucopyranose ring, from C-1 to C-6. Substitution at C-2 may be an acetamido or amino group. Chitosan contains more than $50 \%$ (commonly 70 to $90 \%$ ) of acetamido residues on the C-2 of the structural unit, while amino groups predominate in chitin. The degree of deacetylation (DD) serves as a diagnostic to classify the biopolymer as chitin or chitosan (Dash et al., 2011; Rinaudo, 2006). Notice that DD + DA $=1$.

The DD is the key property that affects the physical and chemical properties of chitosan, such as solubility, chemical reactivity and biodegradability and, consequently their applications. A quick test to differentiate between chitin and chitosan is based on solubility and nitrogen content. Chitin is soluble in 5\% lithium chloride/N,N-dimethylacetamide solvent [LiCI/DMAc] and insoluble in aqueous acetic acid while the opposite is true of chitosan. The nitrogen content in purified samples is less than $7 \%$ for chitin and more than 7\% for chitosan (Dash et al., 2011; Rinaudo, 2006).

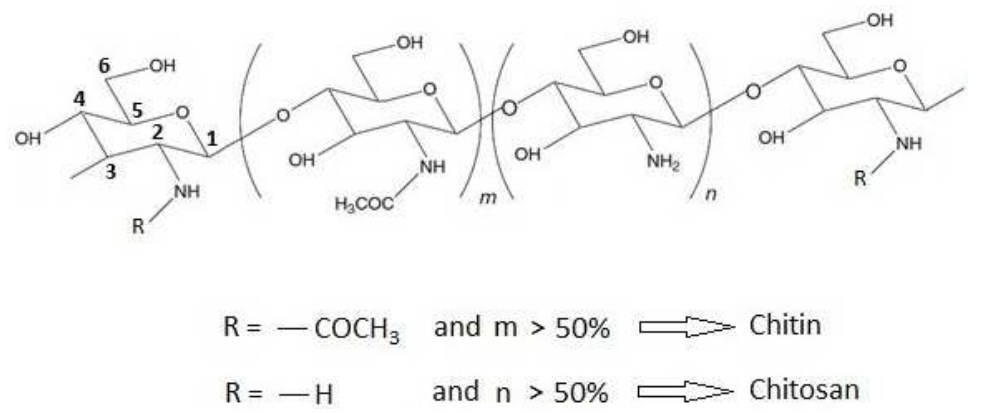

Fig. 1. Chemical structure of chitin and chitosan.

In the solid state, chitosan is a semicrystalline polymer. Its morphology has been investigated and many polymorphs are mentioned in the literature. Single crystals of chitosan were obtained using fully deacetylated chitin of low molecular weight. The dimensions the orthorhombic unit cell of the most common form were determined as $a=$ $0,807 \mathrm{~nm}, b=0,844 \mathrm{~nm}, c=1,034 \mathrm{~nm}$; the unit cell contains two antiparallel chitosan chains, but no water molecules (Dash et al., 2011).

The degree of acetylation (DA) and the crystallinity of chitin molecules affect the solubility in common solvents. Reducing the acetylation level in chitosan ensures the presence of free amino groups, which can be easily protonated in an acid environment, making chitosan 
water soluble below pH about 6.5 (Krajewska, 2004; Lavorgna et al., 2010). In acid conditions, when the amino groups are protonated (Fig. 2), chitosan becomes a soluble polycation (Chivrac et al., 2009). The presence of amino groups make chitosan a cationic polyelectrolyte $(\mathrm{pKa} \approx 6.5)$, one of the few found in nature. Soluble chitosan is heavely charged on the $\mathrm{NH}^{3+}$ groups, it adheres to negatively charged surfaces, aggregates with polyanionic compounds, and chelates heavy metal ions. These characteristics offer extraordinary potential in a broad spectrum of chitosan applications.

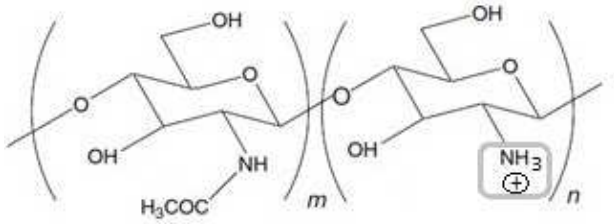

(a)

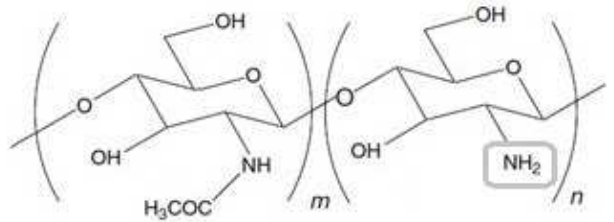

(b)

Fig. 2. Schematic illustration of chitosan: (a) at low $\mathrm{pH}$ (less than about 6.5), chitosan's amine groups become protonated (polycation); (b) at higher $\mathrm{pH}$ (above about 6.5), chitosan's aminegroups are deprontonated and reactive.

Increasingly over the last decade chitosan-based materials have been examined and a number of potential products have been developed for areas such as wastewater treatment (removal of heavy metal ions, flocculation/coagulation of dyes and proteins, membrane purification processes), the food industry (anticholesterol and fat binding, preservative, packaging material, animal feed additive), agriculture (seed and fertilizer coating, controlled agrochemical release), pulp and paper industry (surface treatment, photographic paper), cosmetic sand toiletries (moisturizer, body creams, bath lotion) (No et al., 2000). Owing to the unparalleled biological properties, the most exciting uses of chitosan-based materials are in the area of medicine and biotechnology. Medicine takes advange of its biocompatibility, biodegradability to harmless products, nontoxicity, physiological inertness, remarkable affinity to proteins, hemostatic, fungistatic, antitumoral and anticholesteremic properties; it may be in drug delivery vehicles, drug controlled release systems, artificial cells, wound healing ointments and dressings, haemodialysis membranes, contact lenses, artificial skin, surgical sutures and for tissue engineering. In biotechnology they may find application as chromatographic matrices, membranes for membrane separations, and notably as enzyme/cell immobilization supports (Felt et al., 2000; Krajewska, 2004). The current interest in medical applications of chitosan is easily understood.

Even though a number of potential products have been developed using chitosan-based materials, the tensile properties of pristine chitosan films are poor (due to its crystallinity). Thermal stability, hardness, gas barrier properties and bacteriostatic activity frequently are not good enough to meet the wide ranges of demanding applications. Thus, modification (chemical modification, blending and graft copolymerization) of chitosan has gained importance as means of tailoring the material to the desired properties. In this context, synthesis of nanocomposites with layered silicate loadings was proposed as a novel approach to modify some of the properties of chitosan, including mechanical and thermal behavior (Wang et al., 2005; Wu and $\mathrm{Wu}, 2006$ ), solubility and swelling properties in acidic media (Pongjanyakul et al., 2005), antimicrobial activity (Han et al., 2010; Wang et al., 2006) 
and bioadhesion (Pongjanyakul and Suksri, 2009). Chemical structure of chitosan containing multiple functional groups (hydroxyl, carbonyl, carboxyl, amine, amide) creates new possibilities for bonding chitosan to clays.

\subsection{Clays}

Clays are fine-grained, sedimentary rocks originated from the hydrothermal weathering volcanic volcanic ashes in akaline lakes and seas. As such, clays are classified based on their stratigraphic position, location, and mineral content. Clays contain minerals of definite crystaline structure and elementary composition, some as main components, many as impurities, which usually include organic matter in the form of humic acids. Notwithstanding the fundamental difference between clay and clay mineral, both terms are sometimes used as indistinctly, especially in the frequent occasions in which the clay has a single principal mineral component; in this sense, the clay is considered as the impure mineral and the mineral as the purified clay (Utracki, 2004).

Clays are classified on the basis of their crystal structure and the amount and locations of elelectric charge (deficit or excess) per unit cell. Crystalline clays range from kaolins, which are relatively uniform in chemical composition, to smectites, which vary in their composition, cation exchange properties, and ability to expand. The most commonly employed smectite clay for the preparation of polymeric nanocomposites is bentonite, whose main mineral component is montmorillonite (Utracki, 2004).

Montmorillonite is the name given to clay found near Montmorillonin in France, whereit was identified by Knight in 1896 (Utracki, 2004). Montmorillonite is a 2:1 layered hydrated aluminosilicate, with a triple-sheet sandwich structure consisting of a central, hydrous alumina octahedral sheet, bonded to two silica tetrahedral sheets by shared oxygen ions (Fig. 3). The unit cell of this ideal structure has a composition $\left[\mathrm{Al}_{2}(\mathrm{OH})_{2}\left(\mathrm{Si}_{2} \mathrm{O}_{5}\right)_{2}\right]_{2}$ with a molar

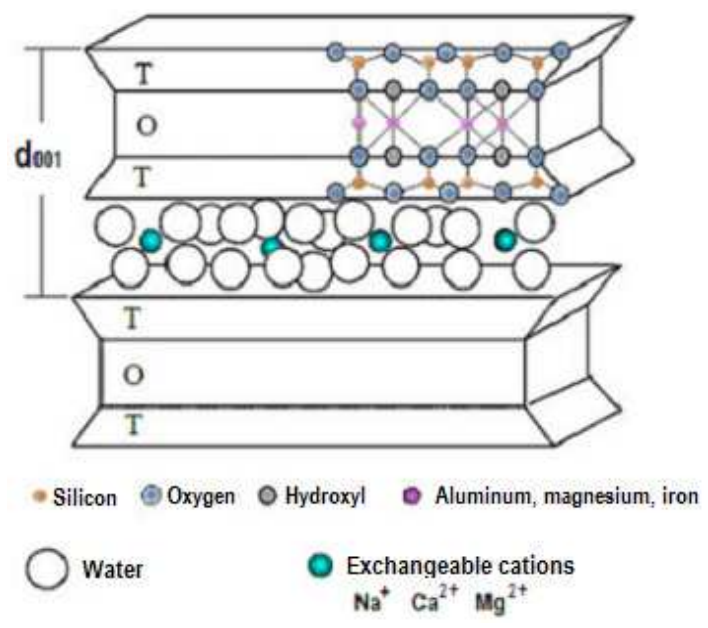

Fig. 3. Schematic of a montmorillonite, layered clay mineral with a triple-sheet sandwich structure consisting of a central, hydrous alumina octahedral sheet $(\mathrm{O})$, bonded to two silica tetrahedral sheets $(\mathrm{T})$ by shared oxygens. 
mass of $720 \mathrm{~g} / \mathrm{mol}$. Isomorphic substitution of $\mathrm{Al}^{3+}$ in the octahedral sheets by $\mathrm{Mg}^{2+}$ (less commonly $\mathrm{Fe}^{2+}, \mathrm{Mn}^{2+}$, and other) and, less frequently, of $\mathrm{Si}^{4+}$ by $\mathrm{Al}^{3+}$ in the tetrahedral sheet, results in a net negative charge on the crystaline layer, wich is compensated by the presence of cations, such as $\mathrm{Na}^{+}, \mathrm{K}^{+}, \mathrm{Ca}^{2+}$, or $\mathrm{Mg}^{2+}$, sorbed between the layers and surrounding the edges. An idealised montmorillonite has 0.67 units of negative charge per unit cell, in other words, it behaves as a weak acid. These loosely held cations do not belong to the crystal structure and can be readily exchanged by other cations, organic or inorganic. The cation exchange capacity (CEC) of montmorillonite ranges from 0.8 to $1.2 \mathrm{meq} / \mathrm{g}$ of air-dried clay, resulting in 0.6-0.9 exchangeable cations per unit cell. The layers organize themselves to form stacks with a regular gap between them, the interlayer space or gallery. The electrostatic and Van der Waals forces holding the layers together are relatively weak, and the interlayer distance varies depending on the radius of the cation present and its degree of hydration. In general, the smaller the cation and the lower its charge, the higher the clay swells in water or alcohols. For montmorillonite, the swelling capacity decreases depending on the cation chemical type according to the following trend: $\mathrm{Li}^{+}>\mathrm{Na}^{+}>\mathrm{Ca}^{2+}>\mathrm{Fe}^{2+}>\mathrm{K}^{+}$(Powell et al., 1998; Tettenhorst et al., 1962, as cited in Chivrac et al., 2009). The distance between two platelets of the primary particle, called inter-layer spacing or d-spacing $\left(d_{001}\right)$, depends on the silicate type, on the type of the counter-cation, and on the hydration state. For instance, $d_{001}=0.96 \mathrm{~nm}$ for anhydrous sodium montmorillonite, but $d_{001}=1.2-1.4 \mathrm{~nm}$ in usual, partially hydrated conditions, as determined by $\mathrm{x}$-ray diffraction techniques (Utracki, 2004).

Commercial montmorillonite is available as a powder of about $8 \mu \mathrm{m}$ particle size, each particle containing about 3000 platelets. Montmorillonite exhibits enhanced gel strength, mucoadhesive capability to cross the gastrointestinal barrier and adsorb bacterial and metabolic toxins such as steroidal metabolites. Because of these advantages in biomedical applications, it is sometimes called a medical clay. Bentonite (named after Ford Benton, Wyoming) is rich in montmorillonite (usually more than 80\%) (Utracki, 2004; Wei et al., 2009; Holzer et al., 2010; Li et al., 2010). Its color varies from white to yellow, to olive green, to brown. The names bentonite and montmorillonite are often used interchangeably. However, the terms represent materials with different degrees of purity. Bentonite is the ore that comprises montmorillonite, inessentials minerals and others impurities. Beyond quartz, kaolinite, and many other minerals often present in minute proportions (feldspar, calcite, dolomite, muscovite, chlorite, hematite, etc), organic matter is present in bentonites as intrinsic impurities composed predominantly of humic substances (Bolto et al., 2001). Since competitive reactions can take place between the organic matter present in the bentonite and the chitosan, the extent of intercalation and polymer/clay interactions can be affected. Purification capable of removing of organic matter from bentonites before intercalation is fundamental.

As mentioned previously, because of the polycationic nature of chitosan in acidic media, the biopolymer may be intercalated in sodium montmorillonite through cation exchange and hydrogen-bonding processes, the resulting nanocomposites showing interesting structural and functional properties.

Chitosan/clay nanocomposites represent an innovative and promising class of materials. Potential biomedical applications of chitosan/clay nanocomposites include: the intercalation of cationic chitosan in the expandable aluminosilicate structure of the clay is expected to affect the binding of cationic drugs by anionic clay; the solubility of chitosan at the low $\mathrm{pH}$ of gastric fluid may decrease the premature release of drugs in the gastric environment; 
cationic chitosan may result in the efficient transport of negatively charged drugs; the presence of reactive amine groups on chitosan may provide ligand attachment sites for targeted drug delivery; etc. The limited solubility of a chitosan/clay nanocomposite drug carriers at gastric $\mathrm{pH}$ offers significant advantages for colon-specific delivery of drugs that may destroyed in the acidic gastric environment or by the presence of gastric digestive enzymes. Furthermore, the mucoadhesive properties of chitosan may enhance the bioavailability of drugs in the gastrointestional tract.

Many actual applications of chitosan/clay nanocomposites are reported in the literature. Darder et al., 2005 prepared chitosan/montmorillonite nanocomposites and used them in potentiometric sensors for anion detection. Gecol et al., 2006 investigated the removal of tungsten from water using chitosan coated montmorillonite biosorbents. Chang and Juang, 2004 studied the adsorption of tannic acid, humic acid, and dyes from water using chitosan/activated clay composites. An and Dultz, 2007 reported the adsorption of tannic acid on chitosan-montmorillonite as well Pongjanyakul et al., 2005; Wang et al., 2005; Wu and $\mathrm{Wu}, 2006$; Günister et al., 2007; Khunawattanakul et al., 2008; Pongjanyakul \& Suksri, 2009. Darder et al. , 2005 synthesized functional chitosan/MMT nanocomposites, successfully used in the development of bulk modified electrodes. Wang et al., 2005 reported the effect of acetic acid residue and MMT loading in the nanocomposites.

However, there are few reports on chitosan/bentonite nanocomposites (Yang \& Chen, 2007; Zhang et al., 2009; Wan Ngah et al., 2010). The physical properties and biological response of chitosan strongly depend on the starting materials and nanocomposite preparation conditions. In the present study chitosan/clay nanocomposites were prepared using two kinds of clay and different chitosan/clay ratios, to evaluate how these variables affect the dispersion of clay particles into the chitosan matrix. The samples obtained were characterized by infrared spectroscopy, x-ray diffraction, and mechanical (tensile) properties.

\section{Experimental}

\subsection{Materials}

Chitosan was supplied by Polymar (Fortaleza, CE, Brazil) and used without purification. The chitosan was obtained by deacetylation of chitin from crab shells, with a degree of deacetylation of $86.7 \%$. Sodium bentonite (Argel 35) was provided by Bentonit União Nordeste (Campina Grande, PB, Brazil). The clay, coded BNT, was purified according to procedure reported elsewhere (Araujo et al., 2007); the cation exchange capacity (CEC) of the purified bentonite was $0.92 \mathrm{meq} / \mathrm{g}$ (Leite et al., 2010). Sodium montmorillonite (Cloisite $\mathrm{Na}+$ ), coded MMT, with a CEC of $0.90 \mathrm{meq} / \mathrm{g}$ was supplied by Southern Clay Products (Gonzalez, TX, USA). Both of the clays, purified sodium bentonite (BNT) and sodium montmorillonite (MMT), were screened to 200 mesh size before mixed with chitosan.

\subsection{Preparation of chitosan films}

Chitosan solutions were prepared by dissolving chitosan in a $1 \%$ aqueous acetic acid solution at a concentration of $1 \mathrm{wt} \%$ under continuous stirring at $45^{\circ} \mathrm{C}$ for $2 \mathrm{~h}$ followed by vacuum filtering to remove the insoluble residue. This solution was cast into Petri dishes (radius $\sim 12 \mathrm{~cm}$ ) and dried at $50^{\circ} \mathrm{C}$ for $20 \mathrm{~h}$ to evaporate the solvent and form the films. The 
dried films were soaked with an aqueous solution of $1 \mathrm{M} \mathrm{NaOH}$ for $30 \mathrm{~min}$ to remove residual acetic acid, followed by rinsing with distilled water to neutralize, and then dried at room temperature. The chitosan films were coded CS.

\subsection{Preparation of the chitosan/clay films}

Chitosan/clay films were prepared by a casting/solvent evaporation technique. Firstly, 1\% chitosan solutions were adjusted to $\mathrm{pH}=4.9$ by addition a $1 \mathrm{M}$ sodium hydroxide solution to form the $\mathrm{NH}^{3+}$ groups in the chitosan structure. Given that the primary amine group in the structure of the chitosan has a $\mathrm{pKa}=6.3,95 \%$ of the groups amine will be protonated at the final $\mathrm{pH}=5$. of the chitosan/clay mixture (Darder et al., 2005). After, the chitosan solution was slowly added to a $1 \mathrm{wt} \%$ clay suspension followed by stirring at $53 \pm 2^{\circ} \mathrm{C}$ for $4 \mathrm{~h}$ to obtain the films with chitosan/clay mass ratios of 1:1, 5:1 and 10:1. This chitosan/clay solution was cast into Petri dishes and dried at $50^{\circ} \mathrm{C}$ for $20 \mathrm{~h}$ to evaporate the solvent and form the films. Following the same procedure used for chitosan films, the dried films were soaked into an aqueous solution of $1 \mathrm{M} \mathrm{NaOH}$ for $30 \mathrm{~min}$ to remove residual acetic acid, followed by rinsing in distilled water to neutral and then dried at room temperature. The chitosan/purified sodium bentonite and chitosan/sodium montmorillonite films prepared from chitosan/clay mass ratio of the 1:1, 5:1 and 10:1 were denoted CS1:BNT1; CS5:BNT1; CS10/BNT1 and CS1:MMT1; CS5:MMT1; CS10:MMT1, respectively.

\subsection{Characterization}

Although the clay dispersion process is usually followed by $\mathrm{x}$-ray diffraction and transmission electron microscopy, infrared spectroscopic techniques may shed light into the complex chemical and physical interactions involved, helping scientists and technologists to understand the mechanisms of nanocomposite formation, and leading to better products and production methods in the laboratory and the industrial plant. Furthermore, infrared spectroscopic is relatively rapid, is a common instrument found in most research laboratories, sample purity is not as critical and the method can be used with insoluble samples. This gives infrared spectroscopic methods an advantage over other methods, which require elaborate and time-consuming sample preparation.

Fourier transform infrared spectra of the chitosan films and the chitosan/clay films were collected using a Spectrum 400 Perkin Elmer operating in the range of $400-4000 \mathrm{~cm}^{-1}$ at a resolution of $4 \mathrm{~cm}^{-1}$.

XRD patterns were obtained using a Shimadzu XRD-6000 diffractometer with $\mathrm{Cu}_{\mathrm{Ka}}$ radiation $(\lambda=0.154 \mathrm{~nm}, 40 \mathrm{kV}, 30 \mathrm{~mA})$ at room temperature. XRD scans were performed on sodium montmorillonite and purified sodium bentonite, chitosan films and chitosan/clay films with a $2 \theta$ range between $1.5^{\circ}$ and $12.0^{\circ}$, at a scanning rate of $1^{\circ} / \mathrm{min}$ and a scanning step of $0.02^{\circ}$. The basal spacing $\left(d_{001}\right)$ value of the layered silicates and the chitosan/layer silicate films were computed using Bragg's law.

Mechanical properties of chitosan films and chitosan/clay films were measured following ASTM D882 standard procedures. The films were cut in rectangular strips $(80 \times 10 \mathrm{~mm})$ and the thickness of each sample was measured at three different locations and averaged. The tensile strength (TS), elastic modulus (EM) and elongation at break (E) of the samples were determined using a universal testing machine (EMIC, model DL1000) fitted with a load cell 
of $50 \mathrm{~N}$, with initial gauge separation of $50 \mathrm{~mm}$ and a stretching speed of $5 \mathrm{~mm} / \mathrm{min}$. Reported results were the average of five independent measurements.

\section{Results and discussion}

\subsection{Infrared spectroscopy (FTIR)}

Fig. 4 shows FTIR spectra in the 4000-400 $\mathrm{cm}^{-1}$ wave number range for sodium montmorillonite (MMT), purified sodium bentonite (BNT), chitosan film (CS),

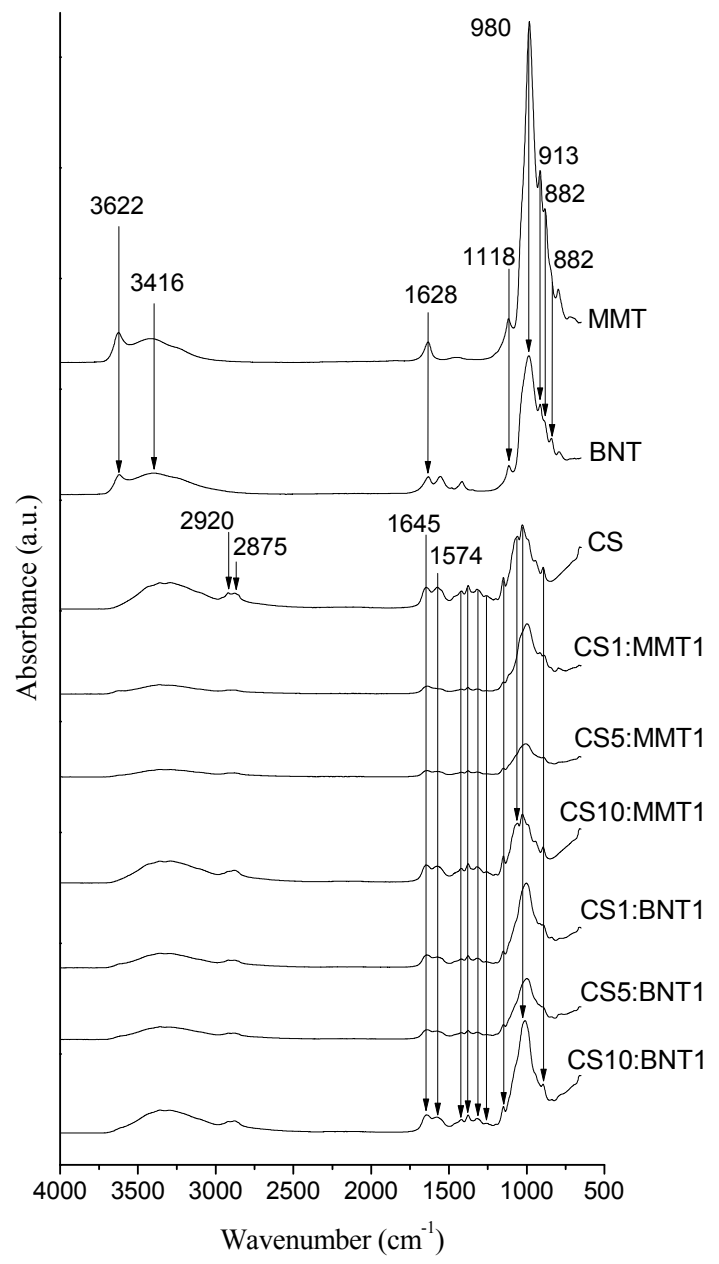

Fig. 4. FTIR spectra in the $4000-400 \mathrm{~cm}^{-1}$ wave number range for sodium montmorillonite (MMT), purified sodium bentonite (BNT), chitosan film (CS), chitosan/MMT and chitosan/BNT films with 1:1, 5:1 and 10:1 chitosan/clay ratios, respectively (CS1:MMT1; CS5:MMT1; CS10:MMT1 and CS1:BNT1; CS5:BNT1; CS10:BNT1). 
chitosan/MMT and chitosan/BNT films with 1:1, 5:1 and 10:1 chitosan/clay ratios, respectively (CS1:MMT1; CS5:MMT1; CS10:MMT1 and CS1:BNT1; CS5:BNT1; CS10:BNT1).

In the clay spectra (MMT and BNT), the characteristic absorption band at $\sim 3622 \mathrm{~cm}^{-1}\left[\mathrm{v}_{\mathrm{OH}}\right]$ is assigned to the stretching vibration of $\mathrm{AlOH}$ and $\mathrm{SiOH}$; at $\sim 3416 \mathrm{~cm}^{-1}\left[\mathrm{v}_{\mathrm{OH}}\right]$ to the stretching vibration of $\mathrm{H}_{2} \mathrm{O}$; at $\sim 1628 \mathrm{~cm}^{-1}\left[\delta_{\mathrm{HOH}}\right]$ to the bending vibration of $\mathrm{H}_{2} \mathrm{O}$; at $\sim 118$ $\mathrm{cm}^{-1}$ and at $\sim 980 \mathrm{~cm}^{-1}\left[v_{\mathrm{Si}-\mathrm{O}}\right]$ to the stretching vibration of $\mathrm{SiO}$; at $\sim 913 \mathrm{~cm}^{-1}\left[\delta_{\mathrm{Al}-\mathrm{Al}-\mathrm{OH}}\right]$ to the bending vibration of $\mathrm{AlAlOH}$; at $\sim 882 \mathrm{~cm}^{-1}\left[\delta_{\mathrm{Al}-\mathrm{Fe}-\mathrm{OH}}\right]$ to the bending vibration of $\mathrm{AlFeOH}$; and at $841 \mathrm{~cm}^{-1}\left[\delta_{\mathrm{Al}-\mathrm{Mg}-\mathrm{OH}}\right]$ to the bending vibration of AlMgOH (Awad et al., 2004; Bora et al., 2000; Leite et al., 2010; Madejová, 2003; Xu et al., 2009).

In order to fully characterize the starting materials, a spectrum of pure chitosan was also recorded. The main bands appearing in that spectrum were due to stretching vibrations of $\mathrm{OH}$ groups in the range from $3750 \mathrm{~cm}^{-1}$ to $3000 \mathrm{~cm}^{-1}$, which are overlapped to the stretching vibration of $\mathrm{N}-\mathrm{H}$; and $\mathrm{C}-\mathrm{H}$ bond in $-\mathrm{CH}_{2}\left(v_{1}=2920 \mathrm{~cm}^{-1}\right)$ and $-\mathrm{CH}_{3}\left(v_{2}=2875 \mathrm{~cm}^{-1}\right)$ groups, respectively. Bending vibrations of methylene and methyl groups were also visible at $v=$ $1375 \mathrm{~cm}^{-1}$ and $v=1426 \mathrm{~cm}^{-1}$, respectively (Mano et al., 2003). Absorption in the range of $1680-1480 \mathrm{~cm}^{-1}$ was related to the vibrations of carbonyl bonds $(\mathrm{C}=\mathrm{O})$ of the amide group CONHR (secondary amide, $v_{1}=1645 \mathrm{~cm}^{-1}$ ) and to the vibrations of protonated amine group $\left(\delta_{\mathrm{NH}_{3}}, v_{2}=1574 \mathrm{~cm}^{-1}\right)$ (Marchessault et al., 2006). Absorption in the range from $1160 \mathrm{~cm}^{-1}$ to $1000 \mathrm{~cm}^{-1}$ has been attributed to vibrations of CO group (Xu et al, 2005). The band located near $v=1150 \mathrm{~cm}^{-1}$ is related to asymmetric vibrations of $\mathrm{CO}$ in the oxygen bridge resulting from deacetylation of chitosan. The bands near 1080-1025 $\mathrm{cm}^{-1}$ are attributed to $v_{\mathrm{CO}}$ of the ring $\mathrm{COH}, \mathrm{COC}$ and $\mathrm{CH}_{2} \mathrm{OH}$. The small peak at $\sim 890 \mathrm{~cm}^{-1}$ corresponds to wagging of the saccharide structure of chitosan (Darder et al., 2003; Paluszkiewicz et al., 2011; Yuan et al., 2010).The assigned characteristic FTIR absorption bands of clay (MMT and BNT) and chitosan film (CS) derived from Fig. 4 are summarized in Table 1.

FTIR was also used to study the polymer/clay interaction, since a shift in the $\delta_{\mathrm{NH}_{3}}$ vibration may be expected when $-\mathrm{NH}_{3}^{+}$groups interact electrostatically with the negatively charged sites of the clay. In fact, a shift of the $\delta_{\mathrm{NH}_{3}}$ band towards a lower frequency is observed in all the chitosan/clay films (CS1:MMT1; CS5:MMT1; CS10:MMT1 and CS1:BNT1; CS5:BNT1; CS10:BNT1) as show in Fig. 5 (spectra of Fig. 4 in the $1800-1400 \mathrm{~cm}^{-1}$ wavenumber range) and Table 2. Nevertheless, this shift is higher for chitosan/clay films with the lowest amounts of chitosan (CS1:MMT1; CS5:MMT1 and CS1:BNT1; CS5:BNT1), while the chitosan/clay films with the highest amounts of biopolymer (CS10:MMT1 and CS10:BNT1) show a frequency value that trends to that observed in the films of pure chitosan (CS). This fact may be related to the $-\mathrm{NH}_{3}^{+}$groups that do not interact electrostatically with the clay substrate (Fig.6). Besides, the intensity of the $\delta_{\mathrm{NH}_{3}}$ band also increases for higher amounts of intercalated chitosan (CS10:MMT1 and CS10:BNT1) (Fig.5). The secondary amide band $\left(v_{1}\right)$ at $1645 \mathrm{~cm}^{-1}$ of chitosan is overlapped with the $\delta_{\mathrm{HOH}}$ bending vibration band at $1628 \mathrm{~cm}^{-1}$ of the water molecules associated to the chitosan/clay films, which are present as in the starting clay, as expected for a biopolymer with high water retention capability (Darder et al., 2003; Darder et al., 2005; Han et al., 2010; Paluszkiewicz et al., 2011; Tan et al., 2007; Wang \& Wang, 2007). Comparing the spectra of chitosan/MMT with the spectra of chitosan/BNT we can observe that the interaction of the chitosan with both clays (MMT and $\mathrm{BNT}$ ) is similar. 


\begin{tabular}{ccc}
\hline Sample & IR band $\left.\mathbf{( c m}^{-1}\right)$ & Description $^{*}$ \\
\hline Clay (MMT and BNT) & 3622 & $v(\mathrm{O}-\mathrm{H})$ for Al-OH and Si-OH \\
3416 & $v(\mathrm{O}-\mathrm{H})$ for H-O-H \\
1628 & $\delta(\mathrm{HOH})$ for H-O-H \\
1118 and 980 & $v(\mathrm{Si}-\mathrm{O})$ out of plane \\
& 913 & $\delta(\mathrm{AlAlOH})$ \\
882 & $\delta(\mathrm{AlFeOH})$ \\
841 & $\delta(\mathrm{AlMgOH})$ \\
Chitosan film (CS) & $3750-3000$ & $v(\mathrm{O}-\mathrm{H})$ overlapped to the $v_{\mathrm{S}}(\mathrm{N}-\mathrm{H})$ \\
& 2920 & $v_{\text {as }}(\mathrm{C}-\mathrm{H})$ \\
& 2875 & $v_{\mathrm{s}}(\mathrm{C}-\mathrm{H})$ \\
& 1645 & $v(-\mathrm{C}=\mathrm{O})$ secondaryamide \\
& 1574 & $v(-\mathrm{C}=\mathrm{O})$ protonated amine \\
& 1426,1375 & $\delta(\mathrm{C}-\mathrm{H})$ \\
1313 & $v_{\mathrm{s}}(-\mathrm{CH})$ tertiary amide \\
1261 & $v(\mathrm{C}-\mathrm{O}-\mathrm{H})$ \\
& 115065,1024 & $v_{a s}(\mathrm{C}-\mathrm{O}-\mathrm{C})$ and $v_{\mathrm{s}}(\mathrm{C}-\mathrm{O}-\mathrm{C})$ \\
& & $\omega(\mathrm{C}-\mathrm{H})$ \\
\hline
\end{tabular}

${ }^{*} v=$ stretching vibration; $v \mathrm{~s}=$ symmetric stretching vibration;

vas $=$ asymmetric stretching vibration; $\omega=$ wagging.

Table 1. Assignment of FTIR spectra of clays and chitosan derived from Fig. 4.

\begin{tabular}{lcc}
\hline \multicolumn{1}{c}{ Sample } & $\delta_{\mathrm{HOH}}\left(\mathbf{c m}^{-1}\right)$ & $\delta_{\mathrm{NH}_{3}}\left(\mathbf{c m}^{-1}\right)$ \\
\hline Clay (MMT and BNT) & $1628^{*}$ & - \\
Chitosan film (CS) & 1645 & 1574 \\
& & \\
Chitosan/MMT (CS1:MMT1) & 1638 & 1555 \\
Chitosan/MMT (CS5:MMT1) & 1640 & 1558 \\
Chitosan/MMT (CS10:MMT1) & 1645 & 1570 \\
& & \\
Chitosan/BNT (CS1:BNT1) & 1640 & 1557 \\
Chitosan/BNT (CS5:BNT1) & 1641 & 1558 \\
Chitosan/BNT (CS10:BNT1) & 1643 & 1570 \\
\hline
\end{tabular}

*stretching band of secondary amide $v(-\mathrm{C}=\mathrm{O})$.

Table 2. Frequency values of vibrational bands corresponding to the water molecules associated with the clay (MMT and BNT) and with the protonated amine group in the chitosan chain. 


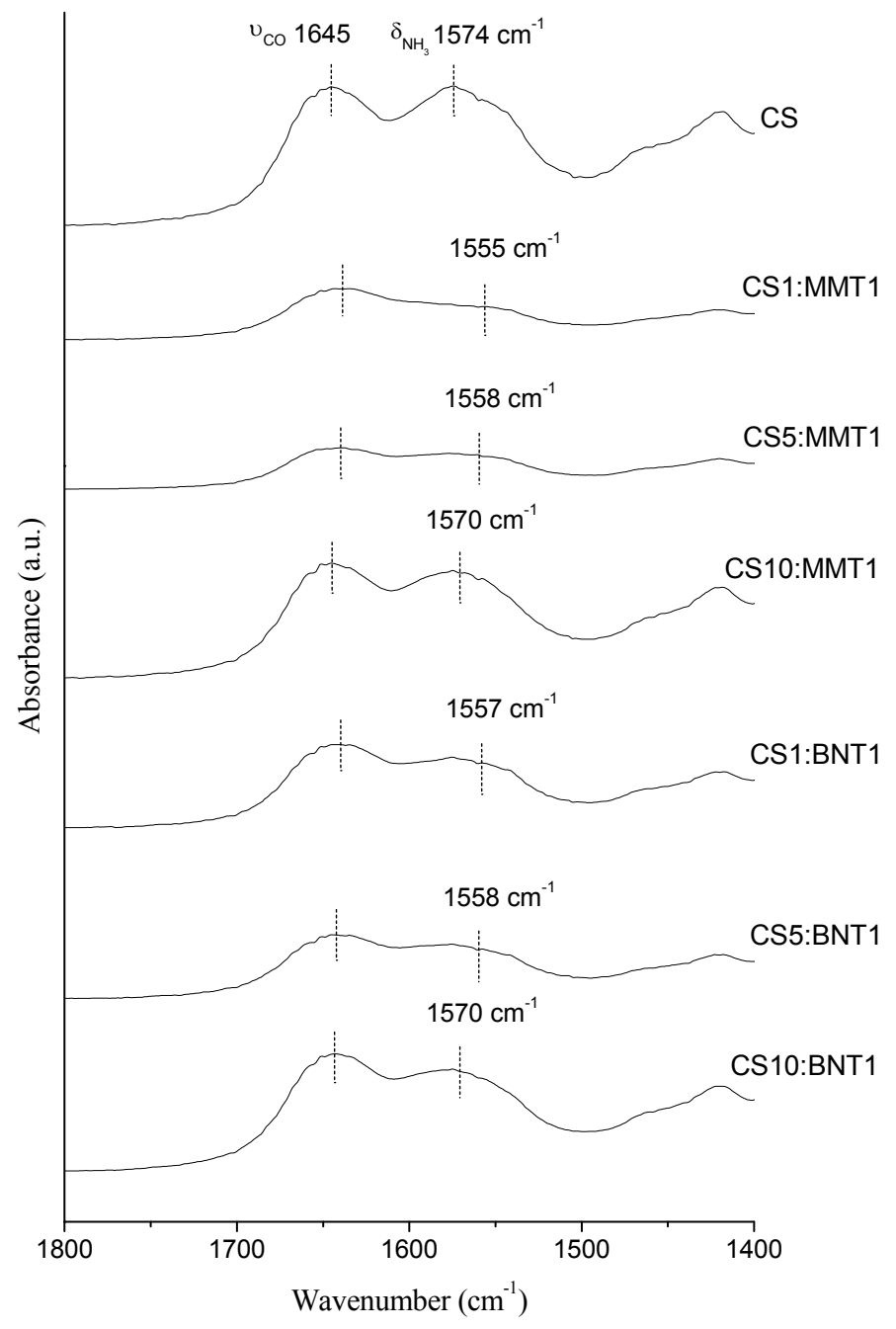

Fig. 5. IR spectra of Fig. 4 in the $1800-1400 \mathrm{~cm}^{-1}$ wavenumber range of chitosan film (CS), chitosan/MMT and chitosan/BNT films prepared from 1:1, 5:1 and 10:1 chitosan-clay ratios (CS1:MMT1; CS5:MMT1; CS10:MMT1 and CS1:BNT1; CS5:BNT1; CS10:BNT1). 


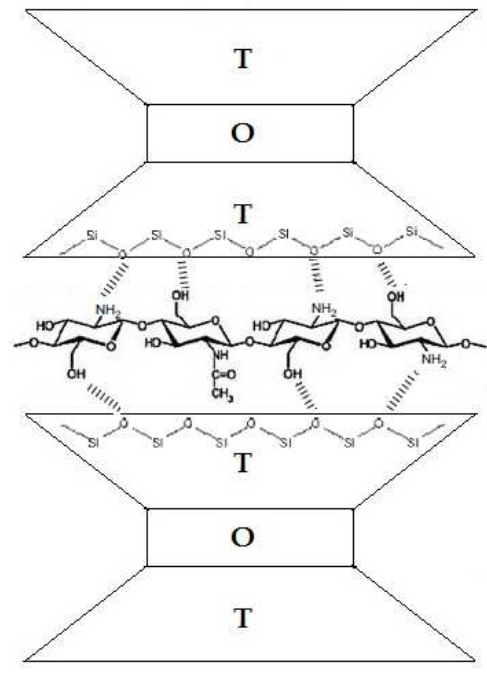

(a)

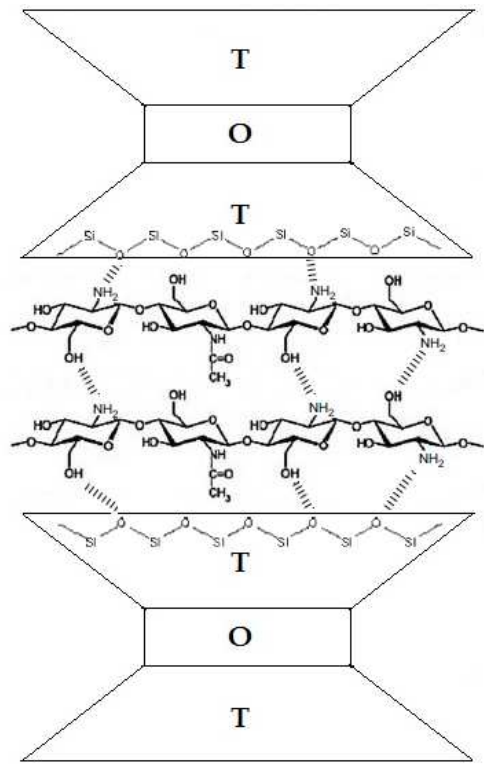

(b)

Fig. 6. Schematic illustration of the intercalation of chitosan layers into the clay inter-layer spacing for films (a) with the lowest amounts of chitosan (CS1:MMT1 and CS1:BNT1) and (b) with the highest amounts of biopolymer (CS10:MMT1, CS5:MMT1 and CS10:BNT1, CS5:BNT1).

\section{$3.2 \mathrm{X}$ ray diffraction analysis (XRD)}

XRD is the principal method that has been used to examine the distribution/dispersion of the clay platelet stacks in the polymer matrix (Utracki, 2004). Depending on the relative distribution/dispersion of the stacks, three types of nanocomposites can be described: intercalated nanocomposites, where polymer chains are interleaved with silicate layers, resulting in a well ordered mutilayer morphology built up with alternating polymer and inorganic sheets; flocculated nanocomposites, where intercalated clay layers are sometimes bonded by hydroxylated edge-edge interactions, and exfoliated/delaminated nanocomposites, where individual clay layers are completely and homogenously dispersed in the polymer matrix (Wang et al., 2005).

FTIR data indicate that chitosan was intercalated into the MMT and BNT interlayers. However, to confirm the FTIR results, the MMT and BNT clays, as well as, chitosan/MMT and chitosan/BNT films prepared from 1:1, 5:1 and 10:1 chitosan/clay ratios, respectively (CS1:MMT1; CS5:MMT1; CS10:MMT1 and CS1:BNT1; CS5:BNT1; CS10:BNT1) were analyzed by XRD and the results are shown in Figs. 7-9.

The XRD patterns of the MMT (Fig. 7) shows a reflection peak at about $2 \theta=5.9^{\circ}$, corresponding to a basal spacing $\left(\mathrm{d}_{001}\right)$ of $1.50 \mathrm{~nm}$. After incorporating MMT within CS, with CS/MMT 1:1 ratio, the basal plane of MMT at $2 \theta=5.9^{\circ}$ disappears, substituted by a new weakened broad peak at around $2 \theta=2.8^{\circ}-3.7^{\circ}$ [CS1:MMT1 (1), CS1:MMT1 (2) and 

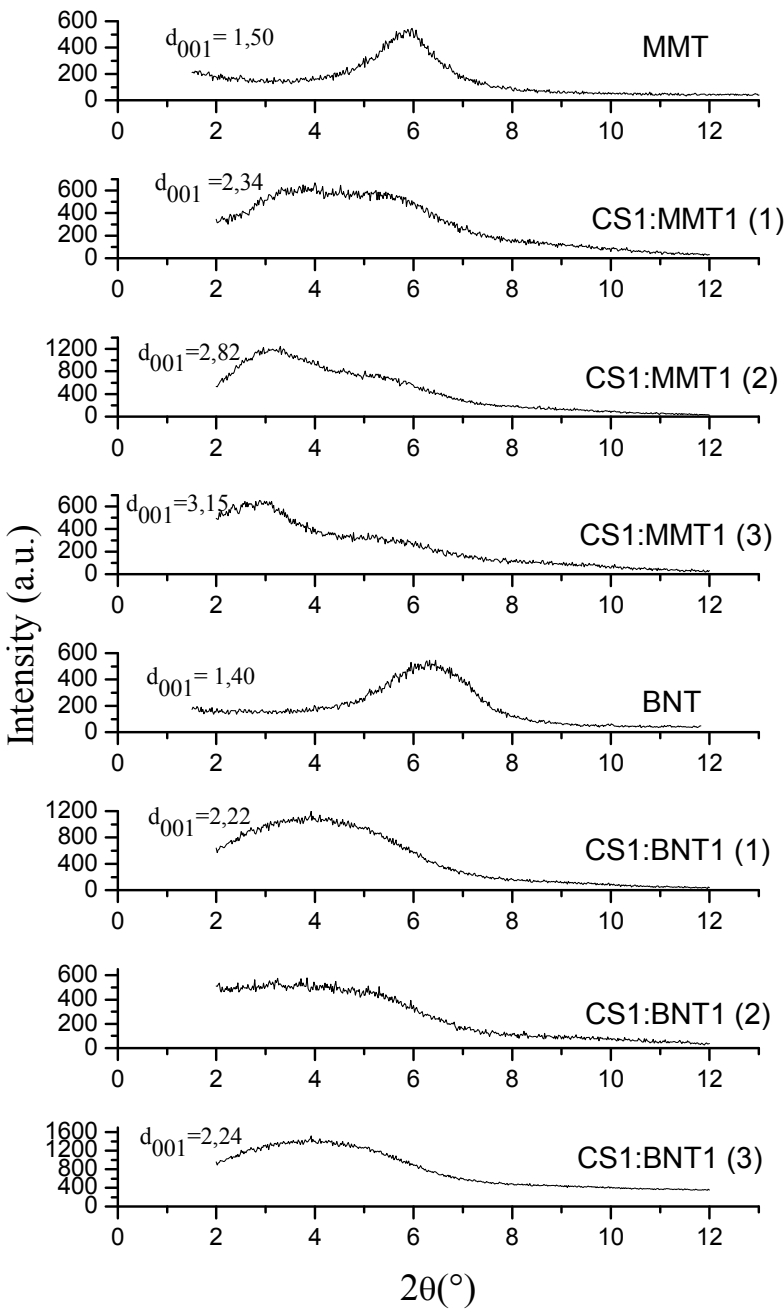

Fig. 7. XRD pattern of sodium montmorillonite (MMT), purified sodium bentonite (BNT), chitosan/MMT and chitosan/BNT films prepared from 1:1 chitosan/clay ratios in triplicate [CS1:MMT1 (1), CS1:MMT1 (2), CS1:MMT1 (3) and CS1:BNT1 (1), CS1:BNT1 (2), CS1:BNT1 (3)].

CS1:MMT1 (3)]. The shift of the basal reflection of MMT to lower angle indicates the formation of an intercalated nanostructure, while the peak broadening and intensity decreases most likely indicate the disordered intercalated or exfoliated structure (Utracki, 2004; Wang et al., 2005). Similar behavior was observed for CS/BNT (Fig. 7), i.e. the basal plane of BNT at $2 \theta=6.3^{\circ}$ disappears, substituted by a new weakened broad peak at around $2 \theta=3.0^{\circ}-3.9^{\circ}$ [CS1:BNT1 (1), CS1:BNT1 (2) and CS1:BNT1 (3)]. It is suggested that the MMT and the BNT form intercalated and flocculated structures. 
Fig. 8 shows he XRD patterns of the MMT, BNT, chitosan/MMT and chitosan/BNT films prepared from 5:1 chitosan/clay ratios in triplicate [CS5:MMT1 (1), CS5:MMT1 (2), CS5:MMT1 (3) and CS5:BNT1 (1), CS5:BNT1 (2), CS5:BNT1 (3)]. After incorporating MMT within CS, with CS/MMT 5:1 ratio, the basal plane of MMT at $2 \theta=5.9^{\circ}$ disappears, substituted by a new weakened broad peak at around $2 \theta=2.0^{\circ}-3.8^{\circ}$ [CS5:MMT1 (1), CS5:MMT1 (2) and CS5:MMT1 (3)]. In this case the $2 \theta$ values were smaller than the values observed for chitosan/MMT prepared from 1:1 ratio (Fig. 7), indicating that exfoliated/delaminated nanocomposites were be obtained. In the same way exfoliated/delaminated nanocomposites are probably obtained for Chitosan/BNT [CS5:BNT1 (1), CS5:BNT1 (2) and CS5:BNT1 (3)].
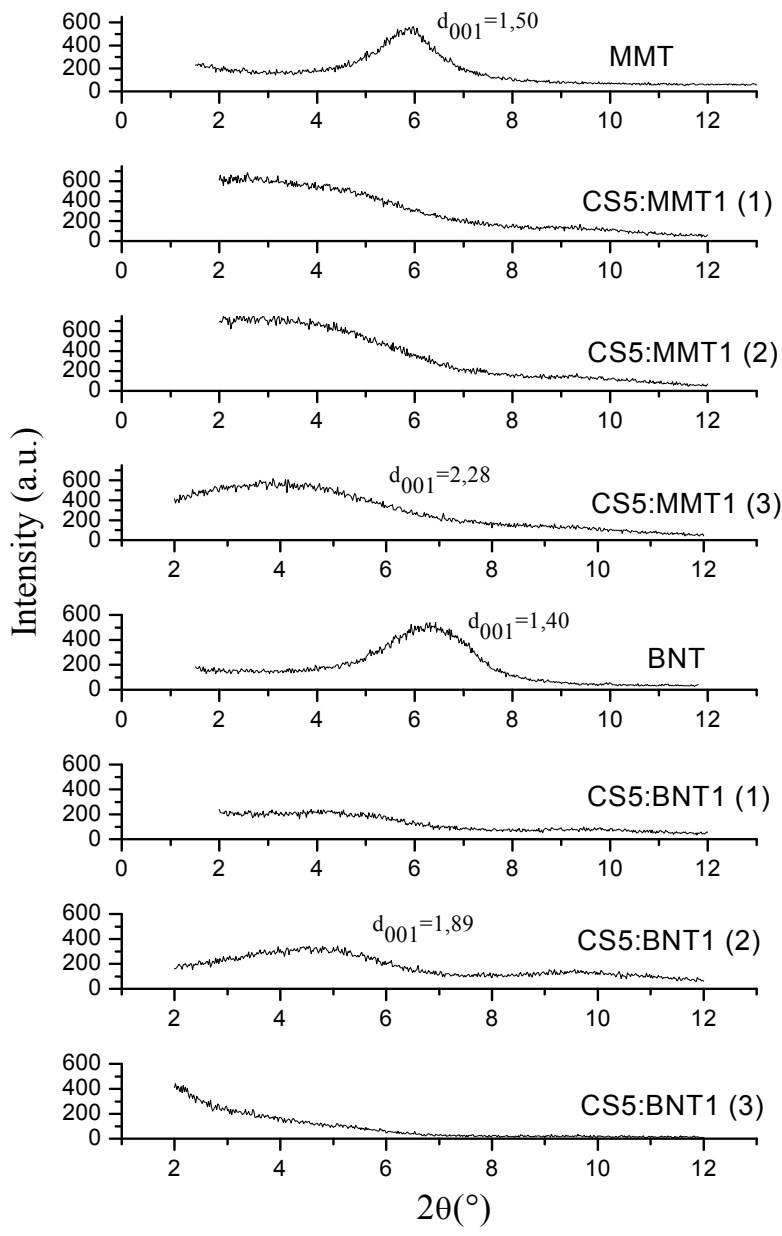

Fig. 8. XRD pattern of MMT, BNT, chitosan/MMT and chitosan/BNT films prepared from 5:1 chitosan/clay ratios in triplicate [CS5:MMT1 (1), CS5:MMT1 (2), CS5:MMT1 (3) and CS5:BNT1 (1), CS5:BNT1 (2), CS5:BNT1 (3)]. 
Fig. 9 shows he XRD patterns of the MMT, BNT, chitosan/MMT and chitosan/BNT films prepared from 10:1 chitosan/clay ratios in triplicate [CS10:MMT1 (1), CS10:MMT1 (2), CS10:MMT1 (3) and CS10:BNT1 (1), CS10:BNT1 (2), CS10:BNT1 (3)]. With increasing CS content, the $2 \theta$ of (001) peak becomes lower and it is not possible to calculate the interlayer distance for each nanocomposite in the broad peaks, indicating that the MMT and the BNT forms intercalated and exfoliated structures. In all probability, exfoliated/delaminated structures were obtained in this case.
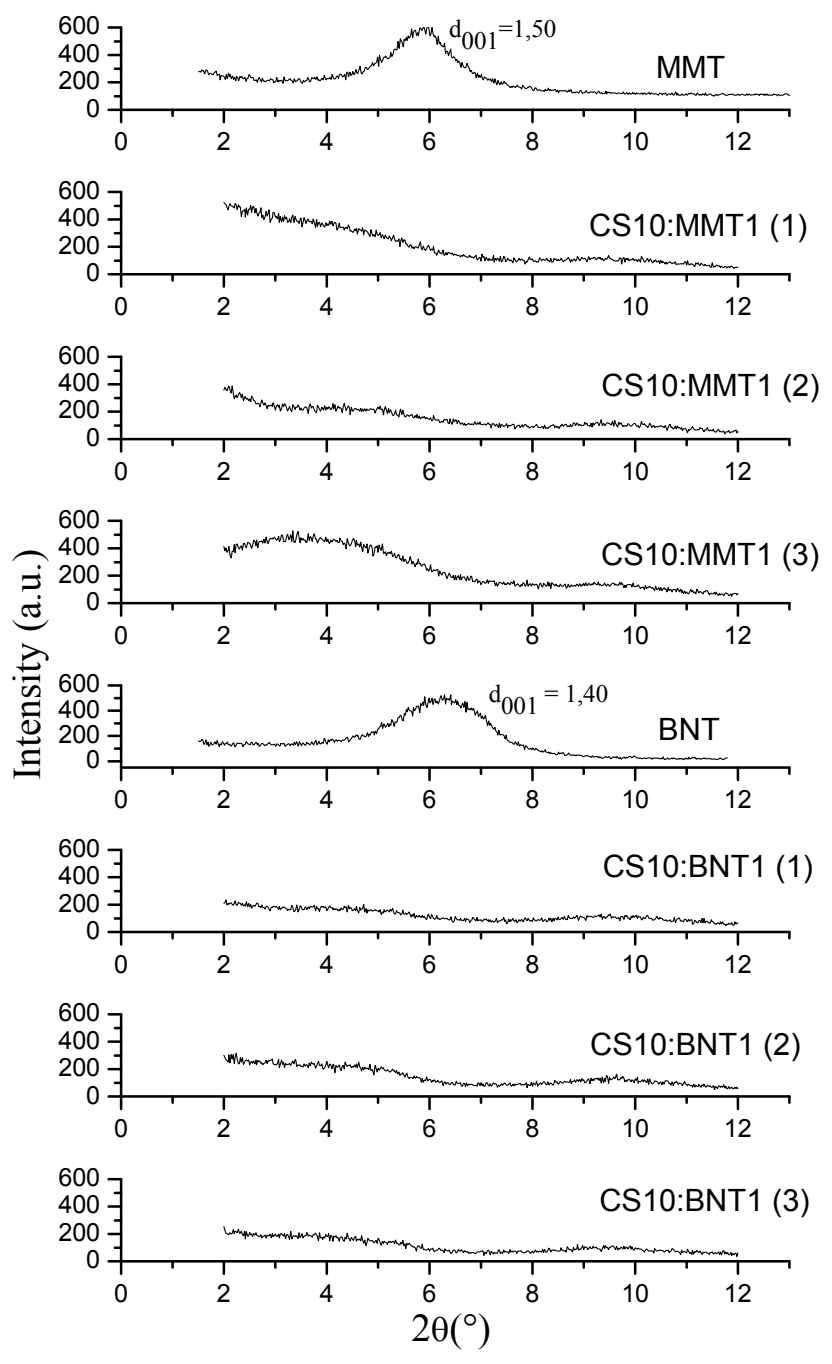

Fig. 9. XRD pattern of MMT, BNT, chitosan/MMT and chitosan/BNT films prepared from 10:1 chitosan/clay ratios in triplicate [CS10:MMT1 (1), CS10:MMT1 (2), CS10:MMT1 (3) and CS10:BNT1 (1), CS10:BNT1 (2), CS10:BNT1 (3)]. 
In summary, the morphology of the nanocomposites was affected by chitosan/clay rations. On the base of XRD patterns, it is suggested that the MMT and the BNT forms intercalated and exfoliated structures at higher CS content (CS10:MMT1, CS5:MMT1 and CS10:BNT1, CS5:BNT1), while decreasing the CS content (CS1:MMT1 and CS1:BNT1), clay layers (MMT and BNT) form intercalated and flocculated structures. According Wang et al., 2005, the formation of flocculated structure in CS/clay nanocomposites can be due to the hydroxylated edge-edge interactions of the clay layers. Since one chitosan unit possesses one amino and two hydroxyl functional groups, these groups can form hydrogen bonds with the clay hydroxyl edge groups, which leads to the strong interactions between matrix and clay layers (Fig.6a) and corroborate FTIR results. This strong interaction is believed to be the main driving force for the assembly of MMT and BNT in the CS matrix to form flocculated structures.

\subsection{Mechanical properties}

Tensile properties of the chitosan film (CS) and chitosan/clay films prepared from 1:1, 5:1 and 10:1 chitosan/clay ratios, respectively (CS1:MMT1; CS5:MMT1; CS10:MMT1 and CS1:BNT1; CS5:BNT1; CS10:BNT1) are collected in Table 3. The tensile strength (TS) and elastic modulus (EM) of chitosan films increase by the formation of nanocomposites, particularly for chitosan/clay prepared from 5:1 rations. The increase in the TS and EM of such nanocomposite films can be attributed to the high rigidity and aspect ratio of the nanoclay as well as the high affinity between the biopolymer and the clay. On the other hand, the chitosan/clay nanocomposites have shown significant decrease in elongation at break (EB). This reduction can be attributed to the restricted mobility of macromolecular chains.

\begin{tabular}{lccc}
\hline \multicolumn{1}{c}{ Sample } & TS (MPa) & EM (MPa) & EB (\%) \\
\hline Chitosan film (CS) & $44.5 \pm 4.5$ & $1774 \pm 63$ & $7.7 \pm 0.5$ \\
Chitosan/MMT (CS1:MMT1) & $84.9 \pm 3.7$ & $5214 \pm 112$ & $3.3 \pm 0.5$ \\
Chitosan/MMT (CS5:MMT1) & $79.1 \pm 1.1$ & $4449 \pm 329$ & $4.6 \pm 0.7$ \\
Chitosan/MMT (CS10:MMT1) & $68.5 \pm 1.4$ & $3536 \pm 180$ & $4.6 \pm 0.8$ \\
& & & \\
Chitosan/BNT (CS1:BNT1) & $49.6 \pm 4.9$ & $4075 \pm 73$ & $2.4 \pm 0.9$ \\
Chitosan/BNT (CS5:BNT1) & $62.1 \pm 4.5$ & $3106 \pm 50$ & $6.8 \pm 0.8$ \\
Chitosan/BNT (CS10:BNT1) & $40.4 \pm 1.8$ & $2421 \pm 87$ & $5.9 \pm 0.8$ \\
\hline
\end{tabular}

(TS = tensile strength, EM = elastic modulus $(\mathrm{EM}), \mathrm{EB}=$ elongation at break)

Table 3. Tensile properties of chitosan and chitosan/clay films.

\section{Conclusions}

In this study chitosan/clay nanocomposites were successfully prepared by the solution intercalation process. It was found that clay dispersion is affected by the kind of clay and the chitosan/clay ratio. Since the nanocomposites prepared with purified bentonite (BNT) showed similar behavior to that prepared with montmorillonite, less expensive bentonite may be employed in the preparation of chitosan/clay nanocomposites. 
The intercalation of the cationic biopolymer chitosan into layered silicate clays (montmorillonite and bentonite) through a cation exchange process results in nanocomposites with interesting structural and functional properties. The clay reduces the film-forming capability of chitosan leading to compact, robust, and handy threedimensional nanocomposites. The techniques employed in the characterization of the nanocomposites, infrared spectroscopy, x-ray diffraction, and mechanical properties in tension, confirm the high affinity between the clay substrate and the biopolymer, as well as the special arrangement of chitosan as a bilayer when the biopolymer amount exceeds the cation exchange capacity of the clay. The intercalation of the first layer of chitosan takes place mainly by electrostatic interactions between positive ammonium groups in the chitosan chain and negative sites in the clay. In contrast, hydrogen bonds between amino and hydroxyl groups of chitosan and the clay substrate are established in the adsorption of the second layer.

\section{Acknowledgments}

This research was financially supported by CAPES, CNPq and INAMI (Brazil). We thank Prof. Heber Carlos Ferreira (Department of Materials Engineering, Federal University of Campina Grande) for graciously proving sodium montmorillonite (Cloisite $\mathrm{Na}^{+}$) samples.

\section{References}

An JH., Dultz S. (2007). Adsorption of tannic acid on chitosan-montmoril-lonite as a function of $\mathrm{pH}$ and surface charge properties. Applied Clay Science. Vol. 36, pp. 25664.

Araujo, P. E. R.; Araújo, S. S.; Raposo, C. M. O.; Silva, S. M. L. (2007). 23th Polymer Processing. Society Annual Meeting. Vol. 23, pp.1.

Awad, W. H.; Gilman, J. W.; Nyden, M.; Harris, R. H.; Sutto, T. E.; Callahan, J.; Trulove, P. C.; Delong, H. C.; Fox, D. M. (2004). Thermal degradation studies of alkylimidazolium salts and their application in nanocompósitos. Thermochimica Acta. Vol. 409, p. 3-11.

Bolto, B.; Dixon, D.; Eldridge, R.; King, S. (2001). Cationic polymer and clay or metal oxide combinations for natural organic matter removal. Water Research.Vol. 35, p. 26692676.

Bora, M.; Ganguli, J. N.; Dutta, D. K. (2000). Thermal and spectroscopic studies on the decomposition of [Ni\{di(2-aminoethyl)amine 2$]-$ and [Ni(2,2":6",2"-terpyridine)2]Montmorillonite intercalated composites Thermochimica Acta. Vol. 346, p.169-175.

Chang, M. Y.; Juang, R. S. (2004). Adsorption of tannic acid, humic acid and dyes from water using the composite of chitosan and activated clay. Journal of Colloid and Interface Science. Vol. 278, pp.18-25.

Chivrac, F.; Pollet, E.; Avérous, L. (2009). Progress in nano biocomposites based on polysaccharides and nanoclays. Materials Science and Engineering R. Vol. 67, pp. $1-17$.

Darder, M.; Colilla, M.; Ruiz-hitzky, E. (2003). Biopolymer-Clay Nanocomposites Based on Chitosan Intercalated in Montmorillonite. ChemicalMaterials. vol. 15, pp. 3774-3780.

Darder, M.; Colilla, M.; Ruiz-Hitzky, E. (2005). Chitosan clay nanocomposites: application as Electrochemical sensors. Applied Clay Science. Vol.28, pp.199-208. 
Dash, M.; Chiellini, F.; Ottenbrite, R.M.; Chiellini E. (2011). Chitosan-A versatile semisynthetic polymer in biomedical applications. Progress in Polymer Science, Vol. 36, pp. 981-1014.

E. S. Costa; H. S. Mansur. (2008). Preparação e caracterização de blendas de quitosana/poli (álcool vinílico) reticuladas quimicamente com glutaraldeído para aplicação em engenharia de tecido. Química Nova. Vol.31, pp.1460-1466.

Felt, O.; Carrel, A.; Baehni, P.; Buri, P.; Gurny, R. (2000) Chitosan as tear substitute: a wetting agent endowed with antimicrobial efficacy. Journal of Ocular Pharmacology and Therapeutics. Vol. 16, pp. 261-270.

Gecol, H.; Miakatsindila, P.; Ergican, E.; Hiibel, S. R. (2006). Biopolymer coated clay particles for the adsorption of tungsten from water. Desalination. Vol. 197, pp. 165-78.

Günister, E., Pestreli, D., Ünlü, C.H.; Güngör, N. (2007). Synthesis and characterization of chitosan-MMT biocomposite systems. Carbohydrate Polymers. Vol. 67, pp.358-365.

Han, Y.; Lee, S.; Choi, K. H. (2010). Preparation andcharacterizationofchitosanclaynanocompositeswith antimicrobial activity. Journal of Physics and Chemistry of Solids. Vol. 71, pp. 464-467.

Holzer, L.; Münch, B.; Rizzi, M.; Wepf, R.; Marschall, P.; Graule, T. (2010). 3D-microstructure analysis of hydrated bentonite with cryo-stabilized pore water. Applied Clay Science. Vol. 47, pp. 330-342.

Khunawattanakul , W.; Puttipipatkhachorn , S.; Rades , T.; Pongjanyakul, T. (2008). Chitosan-magnesium aluminum silicate composite dispersions: characterization of rheology, flocculate size and zeta potential. International Journal of Pharmaceutics. Vol.351, pp. 227-235.

Krajewska, B. (2004). Application of chitin and chitosan-based materials for enzyme immobilizations: a review. Enzyme and Microbial Technology. Vol. 35, pp. 126-134.

Lavorgna, M.; Piscitelli, F.; Mangiacapra, P.; Buonocore, G. (2010). Study of the combined effect of both clay and glycerol plasticizer on the properties of chitosan films. Carbohydrate Polymers. Vol. 82, pp. 291-298.

Leite, I. F.; Soares, A. P. S.; Carvalho, L.H.; Malta, O. M. L.; Raposo, C. M. O.; Silva, S. M. S. (2010). Characterization of pristine and purified organobentonites. Journal of Thermal Analysis and Calorimetry. Vol. 100, pp.563.

Li, Q.; Yue, Q. Y.; Sun, H. J.; Su, Y.; Gao, B. Y. (2010). A comparative study on the properties, mechanism and process designs for the adsorption of non-ionic or anionicdyes onto cationic-polymer/bentonite. Journal of Environmental Management. Vol. 91, pp.16011611.

Madejová, J. (2003). FTIR techniques in clay mineral studies. Vibrational Spectroscopy. Vol.31, pp.1-10.

Mano, J.F.; Koniarova, D.; Reis, R.L. (2003).Journal of Materials Science: Materials in Medicine. Vol. 14, pp.127-135.

Marchessault, R.H.; Ravenelle, F.; Zhu, X.X. (2006). Polysaccharides for drug delivery and pharmaceutical applications, American Chemical Society.

No, H. K.; Lee, K. S.; Meyers, S. P. (2000). Correlation between physicochemical characteristics and binding capacities of chitosan products. Journal Food Science. Vol. 65, pp. 1134-1137. 
Pandey, S. Mishra S. B., (2011). Organic-inorganic hybrid of chitosan/organoclay bionanocomposites for hexavalent chromium uptake, Journal of Colloid and Interface Science. Vol. 361, pp. 509-520.

Paluszkiewicz, C.; Stodolak, E.; Hasik, M.; Blazewicz, M. (2011). FT-IR study of montmorillonite - chitosan nanocomposite materials, Spectrochimica Acta Part A. Vol. 79, pp. 784-788.

Pongjanyakul, T.; Priprem, A.; Puttipipatkhachorn, S. (2005). Investigation of novelalginatemagnesium aluminum silicate microcomposite films for modi fied-releasetablets. Journal Control. Release. Vol. 107, pp. 343- 356.

Pongjanyakul, T.; Suksri, H. (2009). Alginate -magnesium aluminum silicate films forbuccal delivery of nicotine. Colloids and Surfaces B: Biointerfaces. Vol. 74, pp. 103-113.

Rinaudo, M. (2006). Chitin and chitosan: Properties and applications. Progress in Polymer Science.Vol. 31, pp. 603-632.

Tan, W.; Zhang, Y.; Szeto, Y.; Liao, L. (2007). A novel method to prepare chitosan/montmorillonite nanocompósitos in the presence of hydroxyl-aluminum oligomeric cations. Composites Science and Technology.

Utracki, L. A. (2004). Basic Elements of Polymeric Nanocomposite Technology, In: ClayContaining Polymeric Nanocomposites, pp. 73-96, Rapra Technology Limited, England.

Wan Ngah, W. S.; Ariff, N. F. M.; Hanafiah, M. A. K. M. (2010).Preparation, characterization, and environmental application of crosslinked chitosan-coated bentonite for tartrazine adsorption from aqeous solutions. Water, Air and Soil Pollution. Vol. 206, pp.225-236.

Wan Ngah, W. S.; Teong, L. C.; Hanafiah, M. A. K. M. (2011). Adsorption of dyes and heavy metal ions by chitosan composites: A review. Carbohydrate Polymers. Vol. 83, pp. 1446-1456.

Wang, L.; Wang, A. (2007). Adsorption characteristics of Congo Red onto the chitosan/montmorillonite nanocomposite. Journal of Hazardous Materials. Vol. 147, pp. 979-985.

Wang, S. F.; Shen, L.; Tong, Y. J.; Chen, L.; Phang, I. Y.; Lim, P. Q. (2005). Biopolymer chitosan/montmorillonite nanocomposites: Preparation and characterization. Polymer Degradation and Stability. Vol. 90, pp.123-131.

Wang, X.; Du, Y.; Yang, J.; Wang, X.; Shi, X.; Hu Y. (2006). Preparation, characterization and antimicrobial activity of chitosan/layered silicate nanocompósitos. Polymer. Vol. 47, pp. 6738-6744.

Wei, J. M.; Zhu, R. L.; Zhu, J. X.; Ge, F.; Yuan, P.; He, H. P. (2009). Simultaneous sorption of crystal violet and 2-naphthol to bentonite with different CECs. Journal of Hazardous Materials. Vol. 166, pp.195-199.

Wu, T. M.; Wu, C. Y. (2006). Biodegradable poly (lactic acid)/chitosan-modified montmorillonite nanocomposites: preparation and characterization. Polymer Degradation and Stability. Vol. 91, pp. 2198-2204.

Xu, X.; Ding, Y.; Qian, Z.; Wang, F.; Wen, B.; Zhou, H.; Zhang, S.; Yang, M. (2009). Degradation of poly(ethylene terephthalate)/clay nanocomposites during melt extrusion: Effect of clay catalysis and chain extension. Polymer Degradation and Stability. Vol.94, pp.113-123. 
Xu, Y.; Kim, K.; Hanna, M.; Nag, D. (2005). Industrial Crops and Products. Vol. 21, pp. 185192.

Yang, Y. Q.; Chen, H. J. (2007). Study on the intercalation organic bentonite and its adsorption. Journal of Xinyang Normal University. Vol. 20, pp. 338-340.

Yuan, Q.; Shah, J.; Hein, S.; Misra, R.D.K. (2010). Controlled and extended drug release behavior of chitosan-based nanoparticle carrier. Acta Biomaterialia. Vol. 6, pp. 11401148.

Zhang, A. C.; Sun, L. S.; Xiang, J.; Hu, S.; Fu, P; Su, S. (2009). Removal of elemental mercury from coal combustion flue gas by bentonite-chitosan and their modifier. Journal of Fuel Chemistry and Technology. Vol. 37, pp. 489-495. 


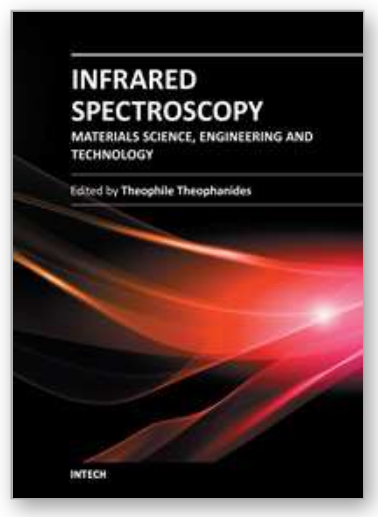

\author{
Infrared Spectroscopy - Materials Science, Engineering and \\ Technology \\ Edited by Prof. Theophanides Theophile
}

ISBN 978-953-51-0537-4

Hard cover, 510 pages

Publisher InTech

Published online 25, April, 2012

Published in print edition April, 2012

The present book is a definitive review in the field of Infrared (IR) and Near Infrared (NIR) Spectroscopies, which are powerful, non invasive imaging techniques. This book brings together multidisciplinary chapters written by leading authorities in the area. The book provides a thorough overview of progress in the field of applications of IR and NIR spectroscopy in Materials Science, Engineering and Technology. Through a presentation of diverse applications, this book aims at bridging various disciplines and provides a platform for collaborations among scientists.

\title{
How to reference
}

In order to correctly reference this scholarly work, feel free to copy and paste the following:

Suédina M.L. Silva, Carla R.C. Braga, Marcus V.L. Fook, Claudia M.O. Raposo, Laura H. Carvalho and Eduardo L. Canedo (2012). Application of Infrared Spectroscopy to Analysis of Chitosan/Clay Nanocomposites, Infrared Spectroscopy - Materials Science, Engineering and Technology, Prof. Theophanides Theophile (Ed.), ISBN: 978-953-51-0537-4, InTech, Available from: http://www.intechopen.com/books/infrared-spectroscopy-materials-science-engineering-andtechnology/application-of-infrared-spectroscopy-to-analysis-of-chitosan-clay-nanocomposites

\section{INTECH}

open science | open minds

\section{InTech Europe}

University Campus STeP Ri

Slavka Krautzeka 83/A

51000 Rijeka, Croatia

Phone: +385 (51) 770447

Fax: +385 (51) 686166

www.intechopen.com

\section{InTech China}

Unit 405, Office Block, Hotel Equatorial Shanghai

No.65, Yan An Road (West), Shanghai, 200040, China

中国上海市延安西路65号上海国际贵都大饭店办公楼 405 单元

Phone: +86-21-62489820

Fax: +86-21-62489821 
(C) 2012 The Author(s). Licensee IntechOpen. This is an open access article distributed under the terms of the Creative Commons Attribution 3.0 License, which permits unrestricted use, distribution, and reproduction in any medium, provided the original work is properly cited. 